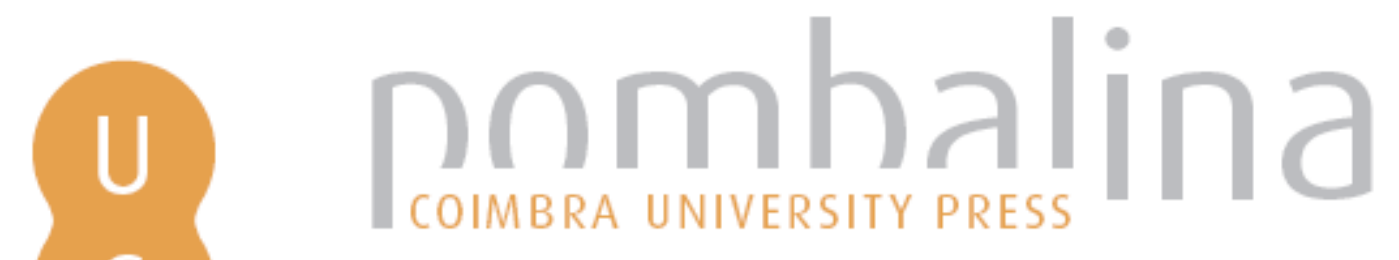

\title{
O trovadorismo galego-português e a Europa
}
Autor(es):
Miranda, José Carlos Ribeiro
Publicado por: Imprensa da Universidade de Coimbra
URL
persistente:
URI:http://hdl.handle.net/10316.2/38948
DOI:
DOI:http://dx.doi.org/10.14195/978-989-26-0395-7_2

Accessed : $\quad$ 26-Apr-2023 16:20:43

A navegação consulta e descarregamento dos títulos inseridos nas Bibliotecas Digitais UC Digitalis, UC Pombalina e UC Impactum, pressupõem a aceitação plena e sem reservas dos Termos e Condições de Uso destas Bibliotecas Digitais, disponíveis em https://digitalis.uc.pt/pt-pt/termos.

Conforme exposto nos referidos Termos e Condições de Uso, o descarregamento de títulos de acesso restrito requer uma licença válida de autorização devendo o utilizador aceder ao(s) documento(s) a partir de um endereço de IP da instituição detentora da supramencionada licença.

Ao utilizador é apenas permitido o descarregamento para uso pessoal, pelo que o emprego do(s) título(s) descarregado(s) para outro fim, designadamente comercial, carece de autorização do respetivo autor ou editor da obra.

Na medida em que todas as obras da UC Digitalis se encontram protegidas pelo Código do Direito de Autor e Direitos Conexos e demais legislação aplicável, toda a cópia, parcial ou total, deste documento, nos casos em que é legalmente admitida, deverá conter ou fazer-se acompanhar por este aviso.

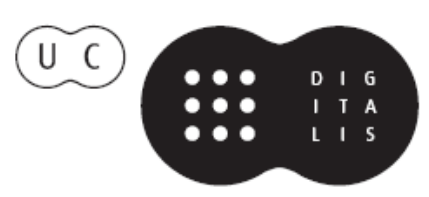


Nair de Nazaré Castro Soares

Santiago López Moreda

Coordenação

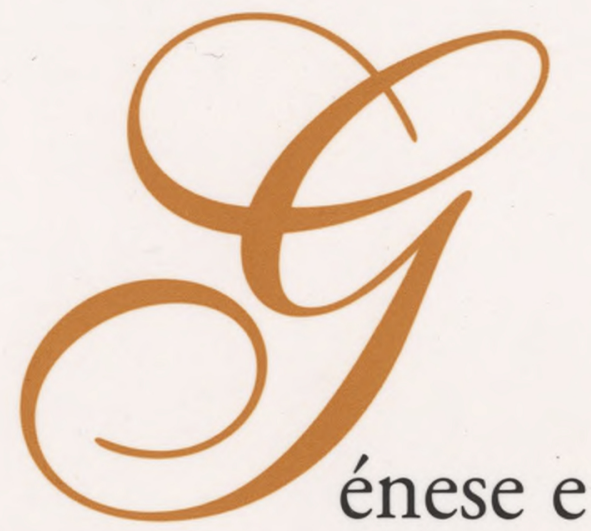

Consolidação da Ideia de Europa

Vol. IV

Idade Média e Renascimento

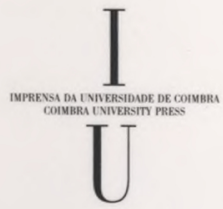

- COIMBra 2009 


\title{
O TROVADORISMO GALEGO-PORTUGUÊS E A EUROPA
}

\author{
JOSÉ CARLOS RIBEIRO MIRANDA
}

(Universidade do Porto)

Ao longo do séc. XII, a Europa ocidental assiste a um conjunto de mutações, cuja dimensão é sobejamente conhecida, afectando todas as esferas da vida dos homens e das sociedades de então. Entre estas mutações, são particularmente relevantes as que incidem especificamente nas esferas da arte, da cultura escrita e do pensamento - há muito designadas pelo conceito genérico "Renascimento do Séc. XII" -, aspectos no seio dos quais há que conferir lugar de relevo à produção literária em línguas vulgares de origem românica. A poesia trovadoresca occitânica ocupa, nesse contexto, um lugar central, não só pela sua muito recuada cronologia, que a faz remontar ainda ao séc. XI, mas sobretudo pela sua dimensão e difusão no conjunto do espaço europeu e nas regiões directamente influenciadas pela Europa, como sucede com as rotas das Cruzadas.

Há, todavia, que compreender que a promoção do occitânico a veículo privilegiado da cultura trovadoresca não se deve a motivos fortuitos mas sim à combinação de duas grandes ordens de factores: em primeiro lugar, é a língua escolhida por um grupo aristocrático dominante para exprimir a sua identidade e a sua independência face ao poder clerical, adquirindo o valor de um capital simbólico que cedo será partilhado pelos vários grupos aristocráticos emergentes um pouco por toda a Europa, mesmo quando não utilizem este idioma no quotidiano; em segundo lugar, foi através da poesia em occitânico que se construiu e divulgou uma linguagem e um conjunto de temas e de atitudes que deram corpo a uma elaborada ideologia aristocrática, centrada na apologia de valores como o serviço vassálico, a prática da dádiva e o amor como vínculo social, que depressa irão encontrar a adesão dos mais poderosos e pujantes estratos da nobreza senhorial situados nos mais diversos quadrantes. 
A Península Ibérica, confinando com o sul de França e possuindo uma intensa rede de ligações ao sul da Europa, dificilmente poderia ficar alheia à vaga trovadoresca e ao predomínio do occitânico. Assim sucedeu em todos os reinos do Norte peninsular que, à excepção do novel reino de Portugal, conhecem a frequência de trovadores occitânicos desde meados do séc. XII, tendo em alguns casos, como o de Aragão, havido uma inserção directa nesse processo literário, através do surgimento de um grupo de trovadores locais que adoptaram o occitânico como língua de "trobar".

A segunda metade do séc. XII é, porém, um período de irradiação mais intensa do fenómeno trovadoresco, que o há-de levar a geografias onde, por questões de valorização e promoção de formas de sociabilidade de âmbito mais restrito, o occitânico poderá vir a ser substituído por outras línguas de maior difusão local.

$\mathrm{Na}$ Península Ibérica, o primeiro núcleo que é possível identificar onde se observa um processo de simultânea convergência e concorrência entre o occitânico e as línguas locais situa-se no Norte de Castela, numa zona próxima da Navarra e de Aragão, mais precisamente no senhorio dos Cameros. Activo após 1190, esse núcleo é sobretudo conhecido por dele ter saído o mais antigo cantar galego-português datável com segurança - o Ora faz ost'o senhor de Navarra, de Joan Soares de Paiva, redigido nos inícios de 1196. Embora não tenha sido possível aceder directamente a mais nenhum texto proveniente da produção deste grupo, o facto de os elementos que o terão integrado - entre os quais, Rui Diaz, o senhor dos Cameros - serem conhecidos antes de mais por estarem presentes na tradição manuscrita da poesia galego-portuguesa leva a pensar que se trataria de um grupo exclusivamente galego-português, o que pode revelar-se não totalmente correcto.

Os Cameros sobressaem pelo apoio que prestaram a vários trovadores occitânicos, desde o tempo de Diego Jiménez até à segunda década do séc. XIII, o que leva a concluir que, nesse meio, se tornou permanente um convívio estreito entre ibéricos e occitânicos. Além disso, conquanto seja visivel a ligação estreita deste núcleo ao Ocidente peninsular, particularmente a Portugal e à zona galega do reino de Leão, a um olhar atento não escapa a presença de castelhanos no seu seio. Por outro lado, não estavam ausentes deste laboratório poético condições propícias a que o castelhano ou outros falares peninsulares fizessem os seus primeiros ensaios. Isso mesmo poderá de algum modo confirmar-se tendo em conta a natureza linguística dos textos deste grupo que terão sido conhecidos e indirectamente utilizados por trovadores occitânicos da dimensão de Raimbaut de Vaqueiras e de Ramon Vidal de Besalú, numa troca literária que terá provavelmente decorrido no âmbito da corte italiana dos marqueses de Monferrato. 
Seja como for, parece também evidente que nem o castelhano, nem qualquer outro falar do centro ibérico acabou por reunir adesões significativas como língua trovadoresca, não apenas porque o galego-português veio a conhecer uma afirmação natural na sequência da ocidentalização deste núcleo senhorial em direcção às suas raízes, mas também porque só Leão, e mais tarde Portugal, se ofereciam como regiões onde se encontravam implantados grupos sociais capazes de reconhecer na linguagem típica do serviço feudo-vassálico os símbolos da afirmação de um poder aristocrático autónomo. O centro peninsular, marcado por formas diversas de organização da realeza e da aristocracia, implicando a uma escassa autonomia desta última, permaneceu naturalmente alheio a este desenvolvimento, sobretudo no tocante à sua adaptação em língua local.

A relação literária e cultural entre o Ocidente ibérico e o Sul de França fluiu, assim, naturalmente, pelo menos até 1220, altura em que evoluções divergentes foram ditando um inevitável afastamento. Mas a primeira geração de trovadores galego-portugueses fica sendo aquela que manteve uma ligação mais estreita à poesia occitânica, traduzida em processos variados de apropriação textual levados a cabo quer pelos peninsulares, quer pelos occitânicos, sinal seguro de que havia relações próximas entre os grupos senhorias que patrocinavam toda esta actividade. Os Cameros, Ricardo Coração-de-Leão, Bonifácio de Monferrato, Afonso IX de Leão, Saveric de Mauléon e até os portugueses Sousões são os nomes das entidades feudais que primeiro ocorrem quando se trata de equacionar a rede de relações trans-europeias que suportaram ou influenciaram as formas da cultura trovadoresca do Ocidente peninsular na fase inicial.

A década de 1220 marca uma viragem fundamental nos rumos do "trobar" galego-português, ditada essencialmente pela extensão, enraizamento e transformação do fenómeno trovadoresco em terras galegas e no reino de Portugal. É por esta altura que surgem modalidades trovadorescas inéditas, entre as quais o cantar de amigo, por entre um quadro geral de afrouxamento da ideologia do serviço de amor e da linguagem vassálica, reconfigurando o imaginário da linguagem poética num sentido denotador de um progressivo afastamento face à ordem do mundo implícita na proposta occitânica. À medida que se vai operando a reformulação dos padrões trovadorescos herdados, com a introdução de elementos formais, temáticos e ideológicos desconhecidos da matriz, mas ajustados ao horizonte vital e ao imaginário específico da formação aristocrática ibérica da orla atlântica, tornam-se menos visíveis as ligações à Europa ao mesmo tempo que se vai afirmando a especificidade galego-portu- 
guesa. Na realidade, é durante este período, nas décadas de 1220 e 1230, que se constitui realmente aquilo que é o fundamental do legado galego-português, vindo a permanecer intangivel para a posteridade apesar das várias convulsões poéticas posteriores.

A mudança desta situação virá a ter lugar ao longo da década de 1230 , sob o efeito conjugado da deslocação para Castela do epicentro do exercício do poder sobre terras galegas, sequente ao fim da coroa leonesa com a morte de Afonso IX, e da progressiva situação de instabilidade política e difusa guerra civil que se vai vivendo no reino de Portugal, culminando com a deposição do rei D. Sancho II em 1245. Raramente é possível marcar de um modo tão preciso o momento da viragem como neste caso, sendo em 1236 que se traça a fronteira que deverá ser tida em conta. Nesse ano, Pero da Ponte, trovador oriundo dos meios galegos mas bem nutrido de hábitos poéticos occitânicos, dá início à proclamação de vistosos louvores fúnebres dirigidos a várias personagens da corte régia castelhana - Haros, Meneses e a própria família real por ocasião do falecimento da rainha Beatriz da Suábia.

Tal como sucedera com alguns dos seus pares, Pero da Ponte tinha já provavelmente abandonado o ambiente galego, onde não mais voltaria a situarse no que à prática do "trobar" e às suas consequências imagético-ideológicas dizia respeito. Embora a operação literária por ele levada a cabo denote a intenção de obter mecenatos no centro da Península que pudessem compensar a situação de enfraquecimento geral, e não apenas aristocrático, dos reinos da orla ocidental ibérica, não deixa de ser também verdade que é em 1236 que o príncipe Afonso, futuro Rei-Sábio, atinge quinze anos de idade e direito a "casa" própria, sendo feito tenente do antigo reino de Leão logo no ano seguinte. Os anos que imediatamente se seguem são ainda marcados pela viagem de sucessivos trovadores galegos e portugueses a Castela, não sendo dificil situá-los na proximidade do jovem príncipe, como se verá.

É também a partir de 1236 que se renovam contactos entre trovadores occitânicos e os meios da corte régia castelhana, interrompidos desde o início do reinado do Rei-Santo. Neste ponto particular, torna-se necessário desfazer alguns equívocos, nomeadamente o da hipotética corte poética que teria existido em torno deste rei. Na realidade, se há referências encomiásticas ao poder castelhano nos trovadores desta época, não encontramos qualquer alusão directa à liberalidade de Fernando III, nem o seu nome é alguma vez pronunciado como personagem polarizadora da actividade trovadoresca. Nem por occitânicos, nem por galego-portugueses. Aliás, o monarca irá mesmo colher opiniões negativas a seu respeito quando Sordello, o Mantuano, trovador occi- 
tânico, vier por estes anos a censurá-lo em tom áspero pela falta das virtudes que elevavam os potentados senhoriais à condição de mecenas de trovadores. Este conjunto de circunstâncias leva a pensar que as grandes esperanças de apoio efectivo e mecenático do mundo trovadoresco se centravam não no rei mas na emergente figura do seu filho. Terá sido, aliás, por esta época, e não mais tarde, que o jovem Afonso "tençoa" em galego-português com o provençal Arnaut Catalan, enquanto este lhe responde em occitânico, documentando na prática em torno de quem circulavam os trovadores da esfera occitânica que encetavam viagem a terras do centro peninsular. É também desta altura outra interessante tenção, entre o português Joan Soares Coelho e Picandon, "segrel" ao serviço de Sordello, reveladora do cosmopolitismo e do espírito de troca literária que se passara a viver em ambiente castelhano sob a proteç̧ão do futuro Rei-Sábio.

Mas o jovem príncipe, já então designado "Rei de Leão" e umbilicalmente ligado à expressão poética em galego-português que não abandonará ao longo de todo o seu trajecto, desde cedo mostrou não ser apenas um mecenas passivo, mero recolector dos benefícios públicos da actividade poético-musical alheia. Conhecia bem o modo poético occitânico e a forma de relacionamento dos trovadores de além-Pirenéus com os poderes senhoriais que os acolhiam, e pôde facilmente confrontar esse modo com a evolução divergente que desde os tempos do seu avô, Afonso IX, rei de Leão, o trovadorismo ibérico vinha conhecendo em terras atlânticas. A sua atitude ter-se-á tornado cada vez mais reservada relativamente à sobranceria $\mathrm{e}$ pouca reverencialidade dos trovadores galego-portugueses oriundos de Portugal e da Galiza, ao desrespeito que revelavam pela ordem fundada no serviço vassálico, tendo assim procurado reorientar os rumos do fazer poético dos que se acolhiam ao seu apoio com o propósito de repor esses valores, que se preservavam ainda intactos nos occitânicos.

É esse o sentido das célebres palavras doutrinárias e programáticas dirigidas por D. Afonso a Pero da Ponte em louvor dos "provençais" e menosprezo da arte de Bernal de Bonaval e de todos os que haviam saído da segunda geração de trovadores sediada em Portugal e na Galiza. Uma vaga de re-provençalização da poesia galego-portuguesa estava em marcha, sendo antes de mais a essa luz que é necessário compreender os rumos do trovadorismo galego-português no período alfonsino.

Pelos dados disponíveis, é facilmente verificável que todo este processo se refina e aprofunda depois da entronização de Afonso X em 1252. Se até então o candidato ao trono régio assumira o seu lugar no seio da aristocracia e agira a partir desse lugar para cristalizar uma pirâmide de prestígio e de poder que arredasse do horizonte qualquer hipótese de rivalidade senhorial, com a 
ocupação do trono castelhano tal projecto vem a adquirir uma outra amplitude e um mais amplo raio de acção. Por um lado, adquirida a supremacia ibérica pela quase total reconquista dos reinos muçulmanos, Afonso $\mathrm{X}$ virá a reclamar o trono imperial do centro da Europa, enquanto por outro congregará junto de si representantes de vários grupos sociais, regionais e religiosos e acolherá a cultura específica desses grupos na pluralidade da sua expressão linguística. $\mathrm{O}$ projecto universalista e globalizante da General Estoria é, em si, a melhor expressão de como este homem procurara transfigurar-se de rei em autêntico axis mundi.

É neste contexto que cresce exponencialmente o apoio prestado aos trovadores quer galego-portugueses, quer occitânicos, particularmente a estes últimos, já que constituíam um extraordinário veículo de divulgação da figura régia e do seu projecto para além do espaço ibérico ao mesmo tempo que consubstanciavam uma forma de exercício do poder e do mando que o monarca não renegava, antes integrava e ultrapassava num projecto muito mais vasto do que o previsto no modelo aristocrático que estava na raíz da cultura trovadoresca. Homens como o genovês Bonifaci Calvo, trovador em occitânico e empenhado panegirista alfonsino, mais adiante também trovador em galegoportuguês, encabeçam um extenso naipe de trovadores que se situam em momentos diversos desta charneira de culturas em que se transformará a corte do Rei-Sábio. Nenhuma corte senhorial ou régia terá alguma vez rivalizado com a intensa actividade tovadoresca propiciada por Afonso, o Sábio, ao longo do seu trajecto como príncipe e como rei, ou poderá vir a fazê-lo, mesmo que tenhamos em mente apenas a quantidade de textos e de autores nessa actividade envolvidos.

Apesar das vicissitudes e, sobretudo, fracassos dos anos finais do reinado de Afonso X, nomeadamente a falência dos projectos imperiais, o apoio régio aos trovadores, e destes ao rei, manteve-se constante, como o prova a figura e a obra de Guiraut Riquier, para muitos o último dos grandes trovadores provençais. Aliás, numa altura em que, noutros prestigiados pontos da Europa, se faziam já sentir as manifestações literárias que iriam assumir e transformar a herança trovadoresca occitânica, a corte alfonsina comportava-se como o último reduto entrincheirado onde essa já arcaica poesia ainda persistia, a par com a galego-portuguesa, embora o decréscimo de trovadoress, de textos e a rarefacção de públicos se fosse tornando inevitável.

De tudo isto, pouco irá sobreviver à morte do rei. O "período alfonsino" não terá qualquer sucessor na corte castelhana onde predominantemente se situara, embora a poesia galego-portuguesa vá ainda prolongar-se na orla atlântica pelo final do século XIII e ainda, numa agonia lenta e persistente, por todo o séc. XIV. A perda de peso político da Galiza trará como efeito que a 
actividade trovadoresca exterior à corte de Afonso X venha a centrar-se sobretudo em Portugal. Mas os círculos afectos à corte de Afonso III, parte deles possuidores de um estágio prolongado em França e noutras paragens da Europa, não farão reflectir senão de um modo episódico esse trajecto externo na produção poética que promoveram. Aliás, a actividade trovadoresca no Ocidente ibérico, confinada a uma dimensão local e de pouco alcance, não produziu ecos noutros pontos da Europa, nem há notícias de intercâmbio ou integração em ambientes europeus promovidos nesta fase a partir do exterior da Península. Apenas se documentam esporádicos contactos entre os meios portugueses e os castelhanos numa altura em que, como dissemos, Afonso $\mathrm{X}$ polarizava em torno de si o fundamental do apoio à actividade trovadoresca.

É assim que, quando D. Dinis, neto do Rei-Sábio, emerge no panorama trovadoresco galego-português, nem o fôlego político externo, nem as ligações matrimoniais do rei e dos seus áulicos a conhecidas estirpes ibéricas, sobretudo aragonesas, farão mais do que promover a apropriação para o galego-português de um obscuro jogral leonês, de seu nome João, que mais adiante se encarregará de fazer as honras fúnebres do grande mas isolado rei-poeta.

É notório que D. Dinis teve um amplo conhecimento quer das tradições poéticas que se haviam forjado na Península, quer do já longínquo legado occitânico, para além de ter sido promotor ou participante de uma actividade literária inovadora que mais adiante viria a dar frutos tanto na escrita romanesca como na historiográfica ou linhagística. Mas nem a memória the foi favorável. O negro esquecimento que se abateu sobre o conjunto do legado galego-português na Península e fora dela, apenas quebrado por algumas vozes isoladas, como a do Marquês de Santillana em pleno séc. XV castelhano, pouco mais fizeram do que ir lembrando que houvera outrora um rei-poeta de seu nome Dinis, sem que isso representasse, no entanto, qualquer conhecimento efectivo do que esse rei alguma vez de facto "trobara"...

Mesmo o seu filho, D. Pedro, Conde de Barcelos, preferirá recordá-lo como exemplo de liberalidade e virtudes senhoriais do que como poeta, conquanto esteja fora de dúvida o conhecimento que possuía da obra poéticomusical do pai, que se dedicou a preservar no seio do conjunto do legado trovadoresco galego-português, embora num ambiente em que já nenhum impacto notável produzia.

Conquanto autor do mais copioso cancioneiro conservado para a posteridade, D. Dinis, "Quel di Portogallo", como dirá Dante, não se tornará conhecido na Europa como trovador, mas apenas como um rei cujas atitudes políticas tiveram alguma importância no mundo de então. 


\section{BIBLIOGRAFIA}

Alvar, Carlos - La poesía trovadoresca en España y Portugal, Barcelona, Editorial Planeta, 1977.

D'Heur, Jean-Marie - Troubadours d'Oc et troubadours galiciens-portugais, Paris, Fundação Calouste Gulbenkian - Centro Cultural Português, 1973.

Frank, István - "Les troubadours et le Portugal", in Mélanges d'Études Portugaises offerts à M. Georges Le Gentil, Lisboa, Instituto para a Alta Cultura, 1949, pp. 199-226.

Le Rayonnement des troubadours, ed. Anton Touber, Amsterdam, Rodopi, 1998.

Meneghett, Maria Luisa - Il publico dei trovatori, Modena, Mucchi Editore, 1984.

MirandA, José Carlos Ribeiro - Aurs Mesclatz ab Argen, Porto, Ed. Guarecer, 2004.

O'Callaghan, Joseph F. - El Rey Sabio. El reinado de Alfonso X de Castilla, Sevilla, Universidad de Sevilla, 1999.

Oliveira, António Resende - Depois do Espectáculo Trovadoresco. A estrutura dos cancioneiros peninsulares e as recolhas dos sécs. XII e XIV, Lisboa, Colibri, 1994.

- O Trovador galego-português e o seu mundo, Lisboa, Editorial Comunicação, 2001.

TAvanI, Giuseppe - A Poesia Lirica Galego-Portuguesa, Lisboa, Editorial Comunicação, 1990.

- Ensaios Portugueses, Lisboa, Imprensa Nacional-Casa da Moeda, 1988.

- Tra Galiza e Provenza. Saggi sulla poesia medievale galego-portoghese, Roma, Carocci editore, 2002. 